\section{Cureus}

Published 12/13/2010

\section{C) Copyright 2010}

Duncan. This is an open access article distributed under the terms of the Creative Commons Attribution License CC-BY 3.0., which permits unrestricted use, distribution, and reproduction in any medium, provided the original author and source are credited.

\title{
Technical Note: Surgical Resection of Intrinsic, Focal Tumors of the Midbrain and Pons
}

\author{
John A. Duncan ${ }^{1}$ \\ 1. Neurosurgery Department, Northern California Kaiser Permanente
}

$\square$ Corresponding author: John A. Duncan, john.a.duncan@kp.org

Disclosures can be found in Additional Information at the end of the article

\section{Abstract}

A single surgeon's series of seven patients undergoing 12 surgical resections within the midbrain and pons for intrinsic low-grade astrocytoma. In six of seven children, local tumor control was achieved over a two to 13 year period with acceptable morbidity and no surgical mortality.

Categories: Pediatric Surgery, Neurosurgery

Keywords: non-exophytic, astrocytoma, brainstem, midbrain, pediatrics, pons

\section{Introduction}

The following is a small surgical series of seven children with intramedullary, non-exophytic, focal tumors of the midbrain and pons. To date, intramedullary brainstem surgery has been most often performed for exophytic tumors or cavernous malformations. These tumors present through the surface in characteristic locations and are classified as cervicomedullary, dorsally exophytic or tectal. Cavernous malformations are most often associated with intramedullary hemorrhage or a cyst extending to the brainstem surface prior to attempted surgical resection.

\section{Technical Report}

In this series, all tumors were not exophytic, but did extend to a brainstem surface. The children's age at presentation ranged from two to 15 years with a follow-up interval of two to 13 years. Twelve total surgical procedures were performed on seven children during this period. Six of seven initial tumors strongly enhanced with intravenous gadolinium, and six of seven tumors had associated cysts or areas of low density within the parenchyma of the brainstem. Six of seven tumors were pilocytic astrocytomas (Grade I/IV) which all enhanced with contrast. One non-enhancing tumor was a low-grade astrocytoma (II/IV) which converted to an autospyproven glioblastoma multiforme (GBM), four years later. A near total resection (>95\%) was achieved in nine surgical procedures based on postoperative imaging within 48 hours. Two patients have had no radiographic progression of disease to date after a single procedure. Tumor progression or recurrence occurred after radiographic near-total resection in four patients requiring five reoperations. One patient died after conversion to GBM.

The surgical procedures performed included the following approaches: 1) interhemispheric, transcallosal, subchoroidal, trans-third ventricular accessing the superior midbrain (Figure 1); 2) suboccipital, transtentorial accessing the tectal region; 3) transtemporal / subtemporal accessing the cerebral peduncle and upper pons (Figure 2); and 4) infratentorial, transcerebellar, middle peduncular accessing the posterior pons. 


\section{Cureus}
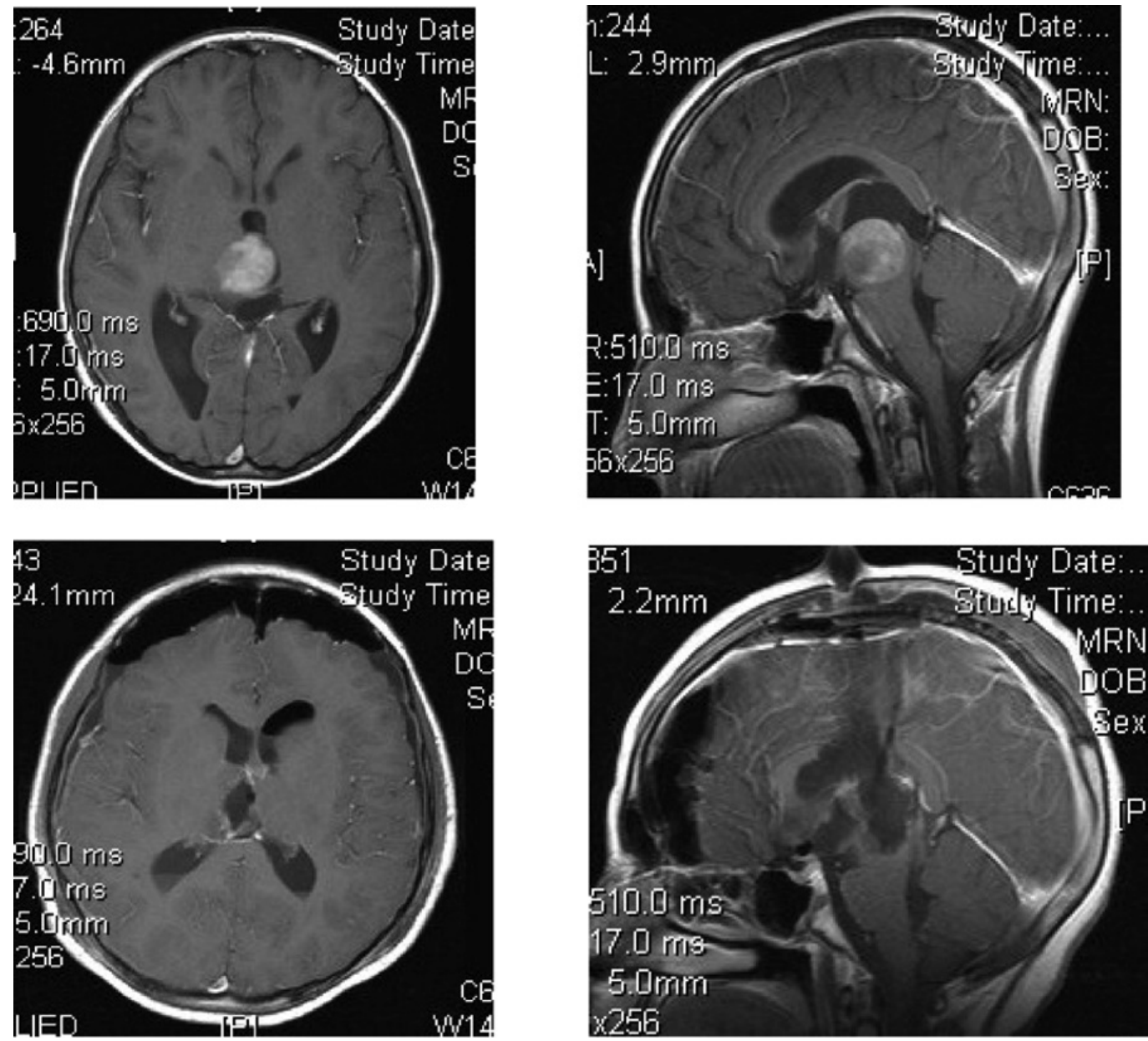

FIGURE 1: Preop above, Postop below
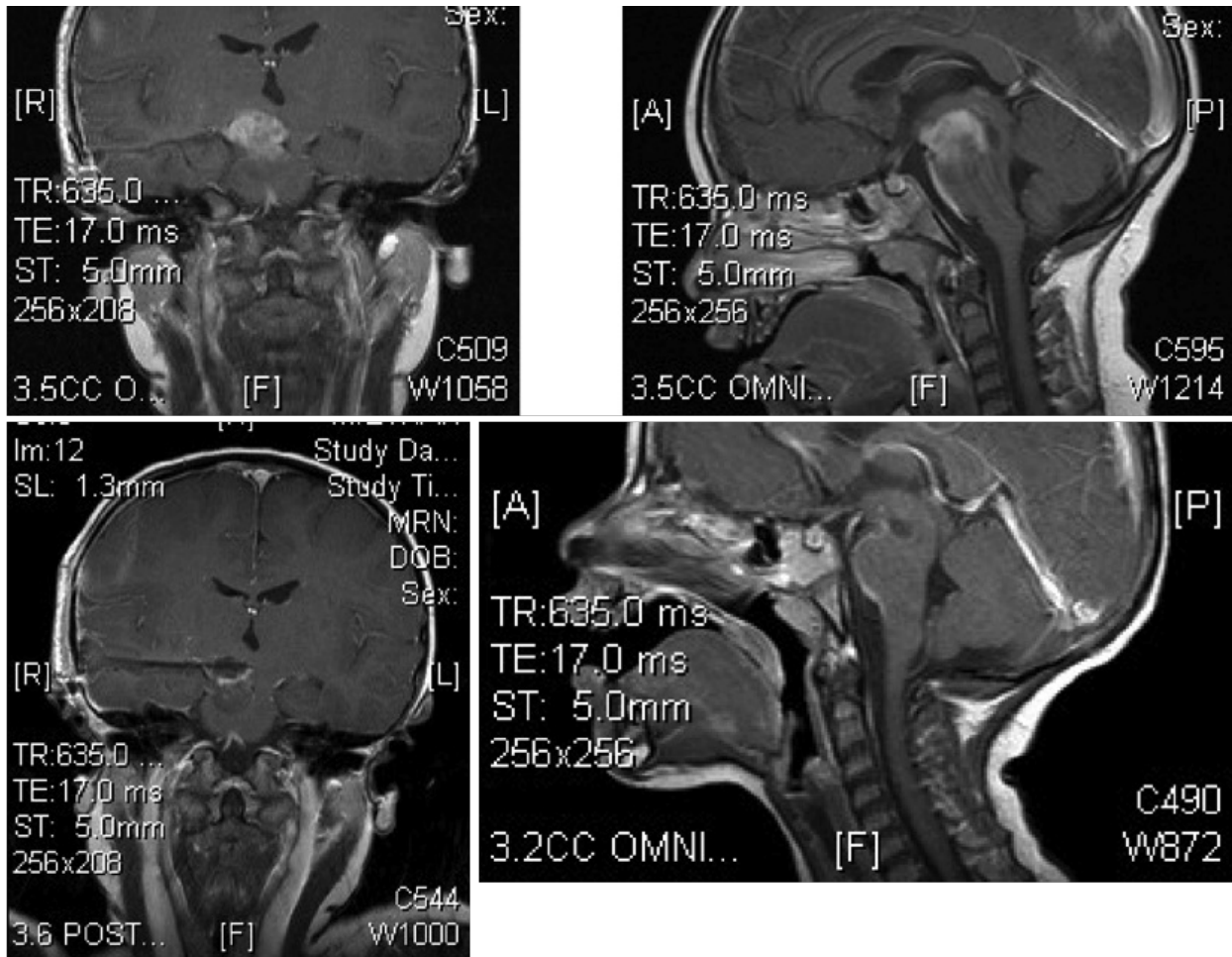
Intraoperative neuronavigation was used in all procedures. The CUSA ultrasonic aspirator set to $30 \%$ vibration and $30 \%$ aspiration was used in all cases and found to be the most beneficial setting for tumor resection. All tumors were grayish in color, gelatinous in texture and relatively avascular. Hemostasis was easily achieved with gentle pressure using cotton or bipolar cautery. Intraoperative neurophysiologic monitoring, which included SSEP and direct motor stimulation, was intermittently employed, but felt to be without intraoperative benefit.

\section{Discussion}

No postoperative permanent morbidity or mortality occurred, with the exception of one permanent nuclear third nerve palsy in one patient on re-resection. Preoperative hemiparesis in three cases all improved with associated cyst decompression and tumor resection.

Today, six of seven children are alive and well. Four of seven are without clinical or radiographic evidence of progressive disease. One of seven, after his second recurrence, was treated with chemotherapy for a histologically stable grade I/IV astrocytoma.

\section{Conclusions}

Surgical resection of intrinsic, focal tumors of the midbrain and pons can be performed safely and is effective in the long-term management of children with intrinsic, low grade astrocytic tumors of the brainstem.

\section{Additional Information}

\section{Disclosures}

Human subjects: All authors have confirmed that this study did not involve human participants or tissue. Animal subjects: All authors have confirmed that this study did not involve animal subjects or tissue. Conflicts of interest: In compliance with the ICMJE uniform disclosure form, all authors declare the following: Payment/services info: All authors have declared that no financial support was received from any organization for the submitted work. Financial relationships: All authors have declared that they have no financial relationships at present or within the previous three years with any organizations that might have an interest in the submitted work. Other relationships: All authors have declared that there are no other relationships or activities that could appear to have influenced the submitted work. 